\title{
Systemic Risks: Intersections between Science and Society with Policy Implications for Sustainability
}

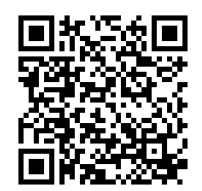

\author{
Klaus Lucas ${ }^{1}$ and Ortwin Renn ${ }^{2 *}$ \\ ${ }^{1}$ Professor, RWTH Aachen University, Germany \\ ${ }^{2}$ Scientific Director, Institute for Advanced Sustainability Studies (IASS), Germany
}

Submission: December 16, 2019; Published: January 06, 2020

*Corresponding author: Ortwin Renn, Scientific Director, Institute for Advanced Sustainability Studies (IASS), Berliner Strasse 130, 14467 Potsdam, Germany

\begin{abstract}
The notion of systemic risks denominates the danger of destruction of a whole system by the mechanisms of nonlinear interactions between its agents in combination with circular causality between the system's elementary dynamic processes and the macroscopic structures generated by them. An extensive body of empirical evidence demonstrates a fundamental homomorphism among systemic risks in all domains, from the systems of nature over those of technology up to society. This homomorphism, based on complexity science, allows to formulate cornerstones of a scientific theory resulting in several governance strategies, associated with policy implications, be it to protect ecosystems, technical infrastructure or, last not least, avoid undesired transformation processes in societies. The approach is exemplified here for the systemic risks associated with modern migration phenomena that has direct impact on sustainable development.
\end{abstract}

Keywords: Sustainable development; Ripple effects; Perturbations; Dynamic structures; Environmental stress

\section{Systemic Risks: Introduction}

At first sight there seems to be no relationship whatsoever between systemic risks such as those posed by global climate change [1] or the present global financial system [2], growing inequalities between rich and poor [3], breakdown of infrastructures [4], as well as the present and urgent local challenges of destruction of ecosystems, mass migration and threat to biological diversity. Still, the existence of universal patterns is unquestionable from empirical evidence. There appear to be common generic mechanisms, i.e. a fundamental homomorphism in the elementary processes responsible for systemic risks in all domains [5]. Closer inspection reveals that systemic risks and the challenges of governance are tightly connected to the complexity of the system. In this context, complexity refers to the difficulty of identifying and quantifying causal links between a multitude of potential elementary processes and their macroscopically visible outcomes. The common properties of complex systems most pertinent for the handling of systemic risks are uncertainty, ambiguity and ripple effects. Uncertainty comprises different and distinct components such as statistical variation, measurement errors, ignorance and indeterminacy [6]. It reduces the strength of confidence in the estimated cause and effect chain(s). Ambiguity denotes the variability of (legitimate) interpretations based on identical observations or data assessments. Most of the scientific disputes in risk analysis do not refer to differences in methodology, data sets, algorithms, models or statistical procedures but rather to the question of what all this means for political measures [7]. Ripple effects are the phenomenon of negative physical impacts (sometimes immediate and obvious, but often subtle and latent) being propagated outside of the domain where the original event is located.

\section{Systemic Risk and Complexity Science}

A more thorough understanding of systemic risks beyond phenomenological analogies is obtained by studying the structure generation processes of simple model systems such as the generation of laser light [8], or the emergence of chemical patterns [9]. Such studies reveal the premises and elementary generic mechanisms associated with the emergence of systemic risks. First, a fundamental premise is the system's openness. It is in exchange with its environment over the system boundaries. This exchange comprises matter, energy and information. Thus, the environment takes part in the processes of the system, having potential impacts on generating as well as mitigating systemic risks. Perturbations may cross the system boundaries and 
destabilize it, governance measures from outside may counteract. Second, systemic risks emerge out of unstable system states. These are generated when the interactions between elementary agents are nonlinear so that small causes may lead to unexpectedly large effects in combination with external or internal stress parameters surpassing a threshold. Such states are characterized by a high sensitivity with respect to external and internal perturbations which is addressed by the well-known butterfly effect.

Third, the emergence of systemic risks appears as an effect of selecting and collective ordering of the elementary processes such as interactions between the agents and feed-back processes of the resulting macroscopic structures upon them, the latter effect being denoted as circular causality. Fourth, the collapse of a stationary structure and the emergence of a new system state is triggered by momentary fluctuations but the deeper reason for it lies in the fact that the system has entered an unstable regime, the origin of which lies in the preceding history of the system. Therefore, any attempts to explain systemic risks from a local and momentary perspective are bound to fail. Fifth, unstable states in complex systems and thus systemic risks announce themselves by early warning signals. Generally, instability is fostered when the interactions between the elements are stronger than friction effects or when damages to system components arise faster than repair mechanisms, e.g. mitigation measures. Finally, complex systems have emergent properties, which means that they can generate structures by self- organization, i.e. without the impact of an external ruler. These structures and the associated systemic risks are coordinated mass phenomena which owe their generation to the interactions between the agents. They thus cannot be deduced from an analysis of the system components nor can they be controlled by central policy measures once they have reached a critical dimension. Based on an understanding of the common generic mechanisms of dynamic structures, and thus also of systemic risks, governance strategies to control them may be identified. Depending on the system under consideration appropriate policy implications present themselves. We here discuss exemplarily some conclusions for the systemic risks associated with modern mass migration and the associated challenges for societal stability.

\section{Modern Mass Migration and Social Stability}

In the modern mass migration phenomena following the Arab uprising the openness of the systems was the basis for information crossing the boundaries of the European-North African countries about better living conditions and about the readiness to assimilate refugees in the European countries. Any effective governance strategy towards mitigation of undesired effects should have taken account of this information transfer and care for an appropriate and stabilizing reaction to it. The dissatisfaction in the Arab society, especially among the young generation, had at the time surpassed a stability threshold. In this situation the self- cremation of a small grocery trader in a small Tunesian village was able to set a widely spread revolution into action. This minor although tragic event, in terms of the generic mechanisms of structure generation, would be classified as a fluctuation, probably without broad consequences in other more stable situations. A sensible governance strategy relies therefore on a permanent monitoring of the society's temper. It is particularly alert to the high sensitivity and suddenness of tipping events and provides political measures to control it.

In modern societies non-linearity of the interactions between agents in combination with circular causality is often based on the disposability of mobile information systems including social media. They allow an instantaneous and widespread distribution of information resulting in rapidly organized mass motions of a large collection of people. During the Arab revolution at first only few and local uprisings manifested themselves. These acted back upon a huge crowd of young people by the massive use of mobile information devices and motivated them to join the movement. Again, by the mechanism of circular causality the new structure of a mass migration movement emerged. In autocratic societies eliminating these services is often used as a governance strategy to control the systemic risk of dispersion of local unrest to an area-wide uprising.

There were early warning signals during all phases of the historical development of the migration crisis, all of them woefully neglected. The instability of the Arab world in the forefront of the uprising clearly was a consequence of its earlier history of suppression by colonialism and later corrupt dictatorships. The lingering but obvious devotion of many parts of the Arab world to fundamentalist Islamic political formations along with an increasing number of local unrests without effective police control was an early indicator of instability. Appropriate governance strategies and political precautions must honor such early warning signals well before the critical instability of the system is reached.

The self-organization of the mass migration following the Arab uprising was an effect of emergence. The agents, notably the young people of the Arab societies, while unsatisfied with their life perspective, were at that time essentially apathetic and shiftless as individuals. However, after the ignition spark of the Tunesian self- cremation and the resulting localized riots, their collective temper in almost all Arab countries changed abruptly and simultaneously to one of mass fury. All measures of the central governments to stop its dispersion failed since the movement had already become a mass phenomenon out of control. The propagating dynamics was stronger than any damping effects. Governance strategies to cope with mass self-organisation in human societies must be based on a thorough analysis of possible measures of de-escalation. Once all applied governance strategies and political measures had dramatically failed mass migration 
presented itself as a wave of unforeseen impact. It became soon clear that the societies which opened themselves for many immigrants from an entirely different cultural background were driven to the edge of instability. In order to fathom appropriate governance strategies and associated political measures on the basis of complexity theory it may be sufficient here to focus on the role of the interactions between the agents, leaving aside the further insights resulting from historicity, sensitivity, emergence, threshold and early warning signals.

In liberal societies stability depends upon an adequate balance of central and self-organization. A transition to instability clearly can be traced back to an unbalance. Self-organization is based upon the interactions between the citizens of the societies and the effects of circular causality, notably associated with the various types of media. While in natural and technical systems these interactions are largely pre-determined, in social systems they are not. Basically, the interaction rules can be hierarchical, competing or cooperative. While hierarchical interactions, which are paradigmatically of the linear type, tend to stabilize a society they are inadequate to unblock any creativity and richness of structures associated with the self-organization on the basis of the highly nonlinear interactions of competition and cooperation. Basically, immigrants and the associated nonlinear interactions with the citizens of the society lead to an increased capacity of collective intelligence and resilience, because one can use the variety of the new agents for the improvement of the flexible adaptation ability. Thus, diverse societies based on nonlinear interactions and circular causality show a fundamental superiority over homogeneous forms of society. Diversity offers better opportunities to adapt to changing environmental conditions and expands the potential of creative solutions for social welfare and security. Adequate governance strategies thus shape the interactions between the citizens by political measures of appreciation and sanctioning. Clearly, the success of such strategies depends on the willingness of the home population as well as of the immigrants to accept and honor these measures.

\section{Sustainability}

It is obvious that mass migrations are partly triggered by environmental crises (for example continuous heat waves) and partly causing unsustainable conditions (new environmental stress as well as risks to social cohesion). Our starting point in examining the connection between complexity, migration and sustainability is the insight that the sustainability conundrum is primarily a societal rather than an environmental problem. The fact that most societal challenges are of the "wicked" kind [10], as well as the need to decide among many societal tradeoffs and many future pathways that may or may not lead to positive results [11], require that we seriously engage in using "Complex Systems" approaches. Whilst there are efforts in this direction, many of those are still only partial [12]. It is up to a combination of complexity and sustainability sciences to identify these pathways. opportunities, and learn how to approach them in a constructive, respectful and peaceful manner, while reducing unintentional effects. Integrating science-informed ideas in such decisions is complex and requires finding a delicate balance between hierarchical, market-based and network-based approaches that provide the conceptual foundation for governance structures and procedures. Migration is one of the core elements of unsustainable living condition and to understand the multiple connections between environmental degradation, economic incentives and policy actions lies at the heart of a scientific investigation of migration based on complexity theories and empirical analysis.

\section{Conclusion}

Systemic risks, here exemplified by those associated with the modern mass migration phenomenon, when analysed based on complexity theory present themselves as phenomena of intersection between science and society. Recognition of the elementary generic mechanisms, as revealed from simple model systems, then allows to derive appropriate governance strategies and political measures to control and mitigate them not easily accessible without this scientific background.

\section{References}

1. IPCC (2014) Climate Change 2014: Synthesis Report. Geneva: IPCC.

2. Lo AW (2012) Reading about the Financial Crisis: A Twenty-one-book Review. Journal of Economic Literature 50(1): 151-178.

3. WEF (2017) The Global Risk Report 2017.

4. Gheorghe AV, Masera M, De Vries L, Weijnen M, Kroeger W (2007) Critical infrastructures: The need for international risk governance. International Journal of Critical Infrastructures 3(1-2): 3-19.

5. Lucas K, Renn O, Jaeger C, Yang S (2018) Systemic risks: a homomorphic approach on the basis of complexity science. International Journal of Disaster Risk Science 9(3): pp. 292-305.

6. van Asselt MBA (2000) Perspectives on Uncertainty and Risk. Dordrecht and Boston: Kluwer.

7. Renn O, Klinke A (2016) Complexity, Uncertainty and Ambiguity in Inclusive Risk Governance. In: Andersen TJ (ed.), The Routledge Companion to Strategic Risk Management. Milton Park, New York: Routledge, pp. 13-30.

8. Haken H (1977) Synergetics. Berlin: Springer.

9. Prigogine I (1980) From being to becoming. San Francisco: WH Freeman.

10. Churchman CW (1967) Wicked Problems [Guest Editorial]. Management Science 14(4): B141-142.

11. Purvis B, Mao Y, Robinson D (2019) Three Pillars of Sustainability: In Search of Conceptual Origins. Sustainability Science 14: 681-695.

12. Schlüter ML, Haider LJ, Steven J, Lad SJ, Lindkvist E, et al. (2019) Capturing emergent phenomena in social-ecological systems: an analytical framework. Ecology and Society 24 (3). 
Your next submission with Juniper Publishers will reach you the below assets

- Quality Editorial service

- Swift Peer Review

- Reprints availability

- E-prints Service

- Manuscript Podcast for convenient understanding

- Global attainment for your research

- Manuscript accessibility in different formats ( Pdf, E-pub, Full Text, Audio)

- Unceasing customer service

Track the below URL for one-step submission https://juniperpublishers.com/online-submission.php 